\title{
Distribution characteristics and policy implications of territorial development suitability of the Yangtze River Basin
}

\author{
TANG Changchun ${ }^{1,2},{ }^{*}$ FAN $\mathrm{Jie}^{2}$, SUN Wei ${ }^{2}$
}

1. School of Civil Engineering and Architecture, Changsha University of Science and Technology, Changsha 410114, China;

2. Institute of Geographic Sciences and Natural Resources Research, Key Laboratory of Regional Sustainable Development Modeling, CAS, Beijing 100101, China

\begin{abstract}
Territorial development suitability (TDS) distribution and policy implications in the Yangtze River Basin are investigated through the use of statistical and spatial data, using the Delphi method, the analytic hierarchy process method and the comprehensive evaluation model. The distribution pattern and characteristics of TDS in the Yangtze River Basin are studied, providing a scientific basis and a decision-making reference for sustainable development of the whole basin, and promoting reasonable implementation of the Yangtze River economic belt development strategy. The results show that the overall level of development constraint is relatively high, and that high-value regions (grades $\mathrm{V}-\mathrm{VIII}$ ) are mainly distributed in the upper and middle reaches of the basin. The suitable development regions account for $22.95 \%$ of the total basin area, mainly including the Yangtze River Delta region, the provincial capitals, the urban agglomerations and most prefecture-level cities. The variation of TDS is significant among the upper, middle and lower reaches of the basin, and the high-value areas account for $8.24 \%, 35.70 \%$ and $82.97 \%$ of the total areas of the upper, middle and lower reaches, respectively. Three policy suggestions are proposed: (1) strict control of the basin development intensity, setting up an efficient and well-organized spatial development pattern, (2) implementation of different regional policies according to different functional orientations, and (3) strengthening of communication and cooperation between different regions, thus promoting integrated basin protection and development.
\end{abstract}

Keywords: territorial development suitability (TDS); distribution; policy; Yangtze River Basin

\section{Introduction}

With the emergence of increasingly prominent issues such as the out of control space de-

\footnotetext{
Received: 2014-11-03 Accepted: 2015-02-10

Foundation: National Social Science Foundation of China, No.09CJL045; National Natural Science Foundation of China, No.41471109; China Postdoctoral Science Foundation Funded Project, No.2011M500377, No.2012T50127

Author: Tang Changchun (1976-), Postdoctoral and Associate Professor, specialized in regional development and land use. E-mail: tangchangchun@163.com

"Corresponding author: Fan Jie (1961-), Professor, specialized in regional development and planning.

E-mail: fanj@igsnrr.ac.cn
} 
velopment and regional disorderly competition, the optimization of development patterns and development of coordinated regions are currently important scientific and practical propositions that need to be solved in China. Furthermore, evaluation of territorial development suitability (TDS) is an important basis that should be taken as a base to solve these propositions. TDS evaluation investigates the suitability of scheduled use and limited status based on the natural and socioeconomic attributes of the land space. In this paper, TDS refers to the suitable degree of the specific space carrying industrialization and urbanization.

International research has mainly focused on the application of geographic information system (GIS) technology and evaluation of model construction. At the end of the 19th century, landscape designers in the USA began to use hand-drawn engineering drawings and superimposed images to evaluate suitability. Since then, an evaluation method based on GIS technology has gradually become the main method of evaluation (He et al., 2009). GIS technology combined with computer-aided overlay graphics (Mac, 1975; Steinitz et al., 1976), multiple-criteria decision-making methods (Carver, 1991; Banai, 1993; Malczewski, 1999; Openshaw and Abrahart, 2000), fuzzy logic (Wang et al., 1990; Burrough and McDonnell, 1998), neural networks (Sui, 1993), genetic algorithms (Krzanowski and Raper, 2001) and cellular automata methods (Batty and Xie, 1994) have gradually improved the evaluation method in terms of comprehensive degree and dynamic accuracy. At the same time, the fusion of GIS technology and another model has become a significant trend. For example, the laboratory at Harvard University etc. developed SYMAP and GRID system consisting of a series of spatial suitability evaluation modules (Murray et al., 1971). However, other researchers have paid more attention to application methods. Ding et al. (2008) divided typical areas of different development intensities according to an index of ecological and economic importance. Qi and Gu (2010) obtained a TDS classification through a comprehensive analysis of three elements and a two-dimensional matrix. Li (2009) demonstrated regionalization of spatial development suitability on a small scale based on a GIS spatial overlay analysis of ecological and economic factors. Sun and Chen (2009) partitioned six suitable development regions using matrix classification of natural ecological constraints and economic development demand analysis. Fan (2011) evaluated the development and construction suitability of a $20-\mathrm{km}$ buffer zone of Xijiang River in China by studying single factor and conducting comprehensive evaluation of nine selected indicators. In practice, the evaluation mainly constituted three indexes: the support capacity of resources and environment, the existing development intensity and the development potential (Fan, 2007). The scale mainly concentrated on the city and the provincial administrative area, while research on interprovincial and basin area was relatively less. In order to widen the content and scale of the current research and deepen the science cognition and theory research of river basin rational development, this paper takes counties as the basic unit to conduct suitability evaluation of the Yangtze River Basin territorial development.

Research on river basin development strategy and policy has realized many achievements. For example, She (1994) studied the development mode and advantage complementary of different sections of the Yangtze River Basin; Wei and Jiang (2009) proposed strategic conception and policy measures of development planning of the Yangtze River Basin; and Chen et al. (2007) gave opinions on policy guidance, the management system and industry posi- 
tioning for land resource development in the Ili River basin. However, these studies were mainly macro-theoretical discussions and qualitative analyses of basin development modes, the scientific content and comprehensiveness need to be further strengthened.

Since the reform and opening up policy in 1978, the gross domestic product (GDP) of the Yangtze River Basin has increased rapidly, with an average annual growth rate of more than $10 \%$. The per capita GDP of major provinces along the whole basin in 2013 was 44,541 yuan, which was higher than the national average level (41,908 yuan). The Yangtze River Basin is an important development axis driving China's economic growth as well as occupying an important position in China's overall pattern of territorial development. At the same time, the basin has obvious regional features at the location, natural conditions, resources and development levels (Zhang, 1991; Chen and Yu, 1997; Liu, 1998; Yu, 2003). With the rapid industrialization and urbanization processes, the Yangtze River Basin faces a series of problems (Liu et al., 2003). These are mainly caused by long-term absence of a strong basin-wide overall plan, as well as disordered territorial development (Wang and Rong, 2010). Therefore, TDS research has significant value in optimizing the layout of spatial development and promoting sustainable development.

\section{Scope of study}

The Yangtze River Basin, in southern China, refers to the watershed area of the Yangtze River's main streams and its tributaries, the area of which is about $1.8 \times 10^{6} \mathrm{~km}^{2}$ and includes 17 whole or part provinces (municipalities and autonomous regions). The basin can be divided into 12 sub-basins, as shown in Figure 1.

The basin is a physical geographical concept. For the convenience of analyzing and providing reference to policy divisions, this article will take county-level administrative areas as the basic unit of analysis. The methods and steps of research on definition of scope are as follows. (1) Overlay the natural boundaries of the Yangtze River Basin with the border of the Chinese administrative division in 2008 using GIS. (2) Determine which county-level divisions belong to the Yangtze River Basin: firstly, those regions that the Yangtze River Basin area takes up to or more than $50 \%$ of the county's total land; secondly, those regions that the Yangtze River Basin area covers less than $50 \%$, but whose county seats are located in the basin; thirdly, those regions that are not able to meet the previous two conditions, but which are largely located in the basin and are of importance in both ecology and location (this mainly refers to the individual counties in the source region of the Yangtze River); and fourthly, Yangzhou City and Jiangdu area are incorporated into the scope of the study, taking the complicated relationship between the Yangtze and Huaihe river basins into account. (3) Merge the city area (except the enclave district) into one unit. In addition, for metropolises, merely merge their inner cities into one unit, and the external part of the city area, which is suburban country and is larger and closer to the county's economic and social characteristics of property, will not be consolidated. On the basis of the above principles, the research scope covers 724 county (district) level administrative regions, in which the upstream areas consist of 305 regions, the middle reaches consist of 318 regions and the lower reaches consist of 101 regions (Figure 1). 


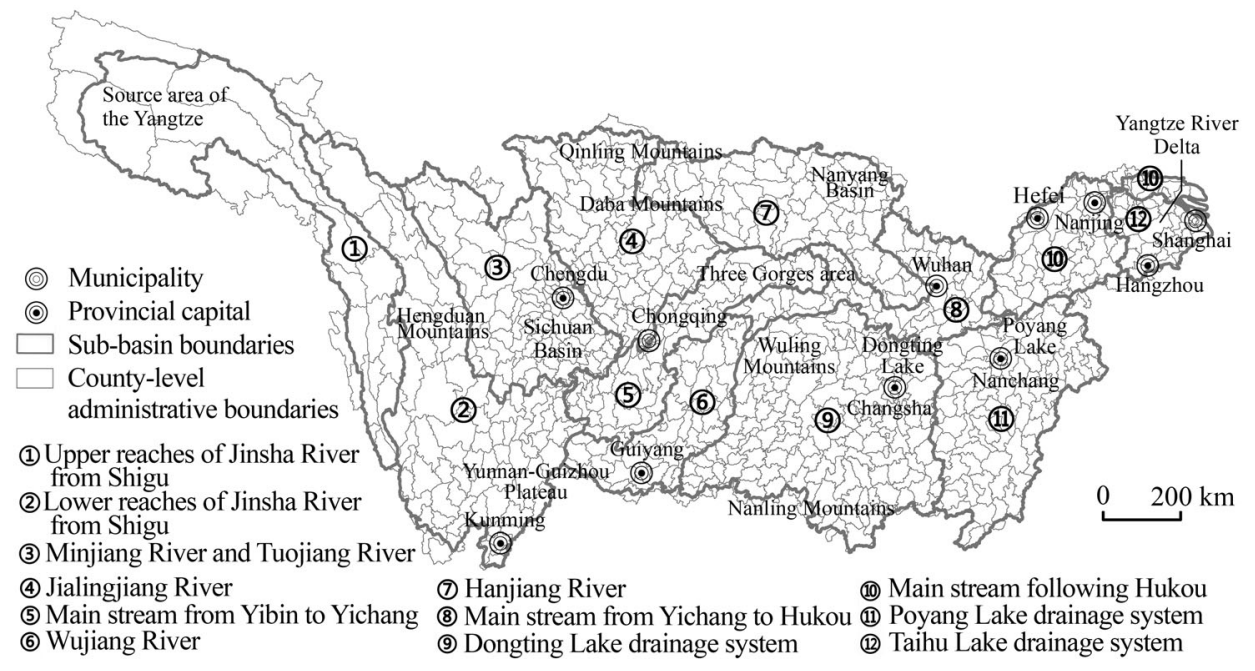

Figure 1 Map showing the location of the study area

\section{Data and method}

\subsection{Data sources and processing}

(1) Statistical data. The statistical data include socioeconomic data and part of the natural resources data in 2008, such as the permanent population, the GDP, the added value in three strata of industry, the rural employment population, the agricultural output value, the investment in fixed assets and the fiscal revenue. These data mainly come from the statistical yearbooks of the provinces (municipalities and autonomous regions) and some prefecture-level cities, and the water resources data base of the water resources bulletin of prefecture-level cities and counties (districts) in 2009 is also used.

(2) Spatial data. The spatial data mainly includes the vector boundaries of the Yangtze River Basin, sub-basins and county-level administrative regions; high-precision digital elevation model data of the basin; land-use distribution data; geological disaster data; data from the railway, freeway, national highway and provincial road networks; and port and channel distribution data. The information was mainly sourced from the basic geographic information center and database in China. All of the data were for the year 2008, except that the land-use distribution data was for the year 2005 and the geological disaster data was for the year 2002.

(3) Comprehensive database of the Yangtze River Basin was built, including the statistical data and spatial data above.

\subsection{Methods and processes}

The order of processes is as follows: choose evaluation objects $\rightarrow$ determine the evaluation unit $\rightarrow$ select the evaluation factors/indexes $\rightarrow$ quantify and classify the evaluation factors/indexes $\rightarrow$ weight factors/indexes $\rightarrow$ evaluate single and comprehensive factors (see Figure 2).

(1) Construction of the evaluation index system. The index system is divided into four 


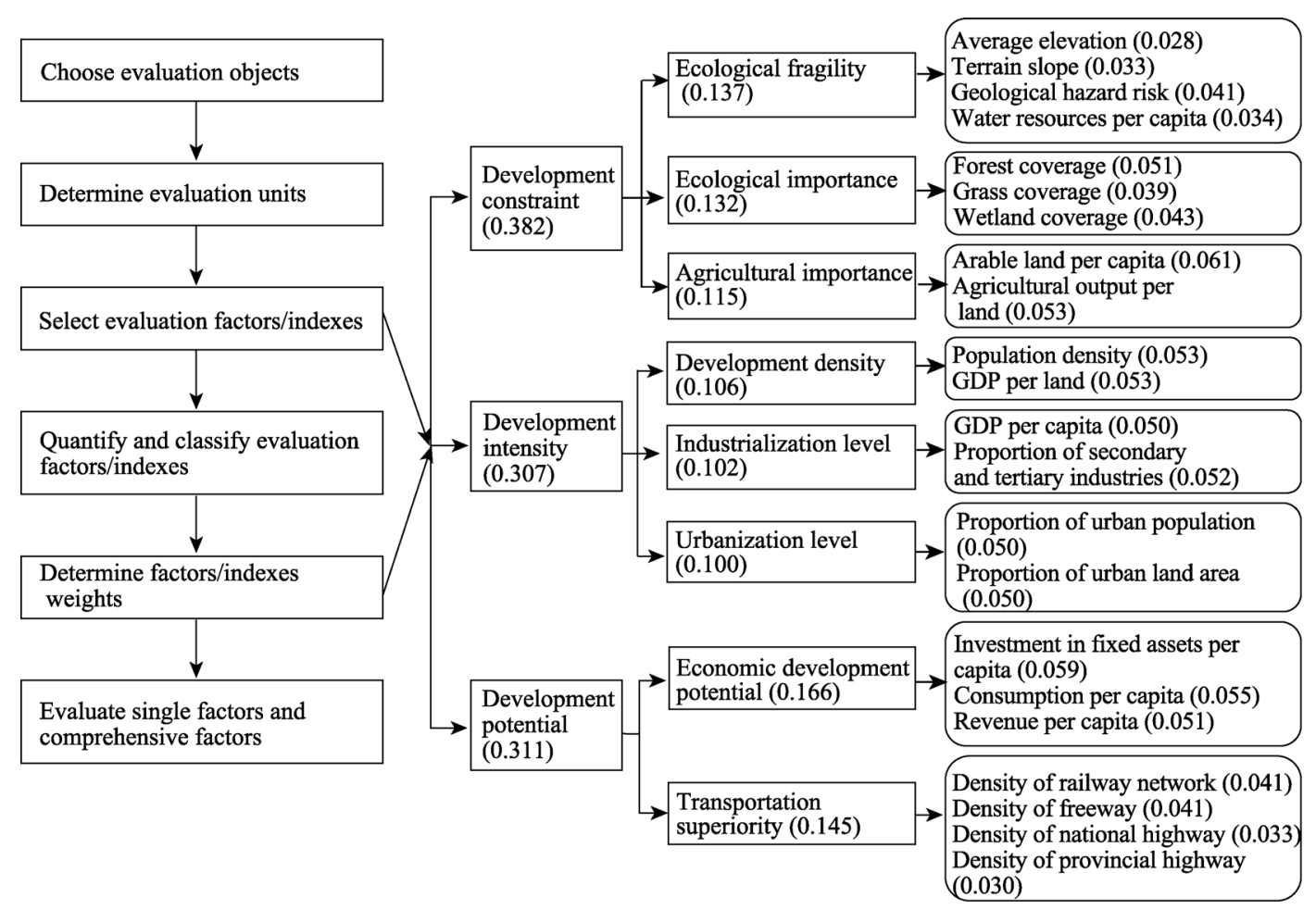

Figure 2 Method route, index system and index weight of comprehensive evaluation of TDS of the Yangtze River Basin

levels: target, criterion, support and feature. The target level refers to TDS. The criterion level includes development constraints, development intensity and development potential. Development constraints consist of three support level indexes: ecological fragility, ecological and agricultural importance, and water resources per capita, arable land per capita and other indexes are included in the feature level index. Development intensity refers to the present development level, which mainly uses the density of development, level of industrialization and urbanization as measurements. The feature level refers to some important indicators such as population and economic density, per capita GDP, industry and population structure, urban land proportion, etc.

Development potential mainly includes two aspects: potential of economic development and superiority of traffic. This paper selects per capita investment, consumption per person and per capita income to measure the potential of regional economic development, and the densities of road networks are used to reflect the superiority of traffic. In addition, the policy factor and non-universal factors are incorporated into qualitative aided analysis. The selection of the index weighting method is one of the key issues in comprehensive evaluation. In this paper, we combine empowerment and confirm weights of evaluation indexes using the Delphi method and an analytic hierarchy process with 22 experts in geography, planning, economics and other research in the upper, middle and lower reaches of the Yangtze River and other regions (Zhu et al., 2007; Guo, 2002) (Figure 2).

(2) Classification and threshold division of single factors. In this paper, single-factor classification combines the reality of the Yangtze River Basin with professional classifica- 
tion knowledge, as well as GIS natural breaking point grading methods. The determination of the data classification level mainly depends on the data set itself and the study of the intrinsic differentiation and complexity (Ge and Feng, 2009). Due to the vast area of the basin and the remarkable differences in natural conditions and socioeconomic development levels, considering the data processing workload and follow-up studies, all single-factor classifications use eight unified levels. The specific classification scheme is shown in Table 1.

Table 1 Partitioning method of threshold intervals of single-factor classification of the Yangtze River Basin

\begin{tabular}{|c|c|c|c|c|c|c|c|c|c|}
\hline \multirow{2}{*}{ Index } & \multirow{2}{*}{$\begin{array}{l}\text { Unit of } \\
\text { measure }\end{array}$} & \multicolumn{8}{|c|}{ Metric threshold value range } \\
\hline & & 1 & 2 & 3 & 4 & 5 & 6 & 7 & 8 \\
\hline Average elevation & $\mathrm{m}$ & $0-200$ & $\begin{array}{c}201- \\
500\end{array}$ & $\begin{array}{l}501- \\
1000\end{array}$ & $\begin{array}{l}1001- \\
2000\end{array}$ & $\begin{array}{c}2001-3 \\
000\end{array}$ & $\begin{array}{c}3001- \\
4000\end{array}$ & $\begin{array}{c}4001- \\
5000\end{array}$ & $>5000$ \\
\hline Average slope & $\circ$ & $0-0.7$ & $\begin{array}{c}0.8- \\
1.7\end{array}$ & $1.8-2.7$ & $\begin{array}{c}2.8- \\
3.9\end{array}$ & $4.0-5.5$ & $\begin{array}{c}5.6- \\
7.6\end{array}$ & $\begin{array}{l}7.7- \\
10.2\end{array}$ & $\begin{array}{l}10.3- \\
15.9\end{array}$ \\
\hline $\begin{array}{l}\text { Geological hazard } \\
\text { risk }\end{array}$ & $\%$ & $0-10$ & $11-20$ & $21-30$ & $31-40$ & $41-55$ & $56-70$ & $71-85$ & $86-100$ \\
\hline $\begin{array}{l}\text { Water resources per } \\
\text { capita }\end{array}$ & $\mathrm{m}^{3}$ & $0-300$ & $\begin{array}{l}301- \\
500\end{array}$ & $\begin{array}{l}501- \\
1000\end{array}$ & $\begin{array}{l}1001- \\
1700\end{array}$ & $\begin{array}{l}1701-2 \\
200\end{array}$ & $\begin{array}{c}2201- \\
3000\end{array}$ & $\begin{array}{l}3001- \\
8000\end{array}$ & $>8000$ \\
\hline Forest coverage & $\%$ & $0-10$ & $11-20$ & $21-30$ & $31-40$ & $41-50$ & $51-65$ & $66-80$ & $81-100$ \\
\hline Grass coverage & $\%$ & $0-10$ & $11-20$ & $21-30$ & $31-40$ & $41-50$ & $51-65$ & $66-80$ & $81-100$ \\
\hline Wetland coverage & $\%$ & $0-2$ & $3-5$ & $6-10$ & $11-15$ & $16-20$ & $21-30$ & $31-40$ & $41-58$ \\
\hline $\begin{array}{l}\text { Arable land per } \\
\text { capita }\end{array}$ & $\mathrm{hm}^{2}$ & $\begin{array}{c}0- \\
0.053\end{array}$ & $\begin{array}{c}0.054- \\
0.10\end{array}$ & $\begin{array}{l}0.11- \\
0.15\end{array}$ & $\begin{array}{c}0.16- \\
0.20\end{array}$ & $\begin{array}{c}0.21- \\
0.30\end{array}$ & $\begin{array}{c}0.31- \\
0.50\end{array}$ & $\begin{array}{c}0.51-0 . \\
80\end{array}$ & $\begin{array}{c}0.81- \\
0.96\end{array}$ \\
\hline $\begin{array}{l}\text { Agricultural output } \\
\text { per land }\end{array}$ & $\begin{array}{c}10000 \\
\text { yuan } / \mathrm{km}^{2}\end{array}$ & $0-50$ & $\begin{array}{l}51- \\
100\end{array}$ & $101-150$ & $\begin{array}{l}151- \\
200\end{array}$ & $\begin{array}{c}201- \\
300\end{array}$ & $\begin{array}{c}301- \\
400\end{array}$ & $\begin{array}{c}401- \\
600\end{array}$ & $\begin{array}{c}601- \\
968\end{array}$ \\
\hline Population density & $\begin{array}{c}\text { Persons/ } \\
\mathrm{km}^{2}\end{array}$ & $0-10$ & $11-50$ & $51-200$ & $\begin{array}{c}201- \\
500\end{array}$ & $\begin{array}{l}501- \\
1000\end{array}$ & $\begin{array}{l}1001- \\
3000\end{array}$ & $\begin{array}{c}3001- \\
6000\end{array}$ & $>6000$ \\
\hline GDP per land & $\begin{array}{c}10000 \\
\text { yuan } / \mathrm{km}^{2}\end{array}$ & $0-250$ & $\begin{array}{l}251- \\
500\end{array}$ & $\begin{array}{l}501- \\
1000\end{array}$ & $\begin{array}{l}1001- \\
2000\end{array}$ & $\begin{array}{c}2001- \\
4000\end{array}$ & $\begin{array}{l}4001- \\
10000\end{array}$ & $\begin{array}{l}10001- \\
50000\end{array}$ & $\begin{array}{l}50001- \\
140000\end{array}$ \\
\hline GDP per capita & yuan & $\begin{array}{c}2335- \\
7000\end{array}$ & $\begin{array}{l}7001- \\
14000\end{array}$ & $\begin{array}{c}14001-2 \\
1000\end{array}$ & $\begin{array}{c}21001- \\
28000\end{array}$ & $\begin{array}{c}28001- \\
35000\end{array}$ & $\begin{array}{c}35001- \\
70000\end{array}$ & $\begin{array}{l}70001- \\
140000\end{array}$ & $>140000$ \\
\hline $\begin{array}{l}\text { Proportion of secon- } \\
\text { dary and tertiary } \\
\text { industries }\end{array}$ & $\%$ & $0-30$ & $31-50$ & $51-60$ & $61-70$ & $71-80$ & $81-90$ & $91-95$ & $96-100$ \\
\hline $\begin{array}{l}\text { Proportion of employed } \\
\text { population in rural areas }\end{array}$ & $\%$ & $0-5$ & $6-10$ & $11-15$ & $16-20$ & $21-30$ & $31-40$ & $41-50$ & $51-55$ \\
\hline Proportion of urban land & $\%$ & $0-0.10$ & $\begin{array}{c}0.11- \\
0.20\end{array}$ & $\begin{array}{c}0.21- \\
0.50\end{array}$ & $\begin{array}{l}0.51- \\
2.50\end{array}$ & $\begin{array}{c}2.51- \\
5.00\end{array}$ & $\begin{array}{l}5.01- \\
10.00\end{array}$ & $\begin{array}{c}10.01- \\
30\end{array}$ & $>30$ \\
\hline $\begin{array}{l}\text { Investment in fixed } \\
\text { assets per capita }\end{array}$ & yuan & $\begin{array}{c}168-38 \\
00\end{array}$ & $\begin{array}{c}3801- \\
7000\end{array}$ & $\begin{array}{c}7001-10 \\
000\end{array}$ & $\begin{array}{l}10001- \\
15000\end{array}$ & $\begin{array}{l}15001- \\
20000\end{array}$ & $\begin{array}{l}20001- \\
30000\end{array}$ & $\begin{array}{c}30001- \\
40000\end{array}$ & $\begin{array}{c}40001- \\
61000\end{array}$ \\
\hline $\begin{array}{l}\text { Consumption per } \\
\text { capita }\end{array}$ & yuan & $\begin{array}{l}500- \\
2000\end{array}$ & $\begin{array}{l}2001- \\
3000\end{array}$ & $\begin{array}{c}3001- \\
4000\end{array}$ & $\begin{array}{c}4001- \\
6000\end{array}$ & $\begin{array}{l}6001- \\
10000\end{array}$ & $\begin{array}{l}10001- \\
15000\end{array}$ & $\begin{array}{c}15001- \\
25000\end{array}$ & $\begin{array}{c}25001- \\
44000\end{array}$ \\
\hline Revenue per capita & yuan & $0-450$ & $\begin{array}{l}451- \\
1000\end{array}$ & $\begin{array}{l}1001- \\
2000\end{array}$ & $\begin{array}{c}2001- \\
3000\end{array}$ & $\begin{array}{c}3001- \\
4500\end{array}$ & $\begin{array}{l}4501- \\
7500\end{array}$ & $\begin{array}{l}7501- \\
11500\end{array}$ & $\begin{array}{l}11501- \\
22000\end{array}$ \\
\hline $\begin{array}{l}\text { Trunk road network } \\
\text { density }\end{array}$ & $\mathrm{km} / \mathrm{km}^{2}$ & $0-0.02$ & $\begin{array}{c}0.03- \\
0.05\end{array}$ & $0.06-0.10$ & $\begin{array}{c}0.11- \\
0.15\end{array}$ & $0.16-0.20$ & $0.21-0.30$ & $0.31-0.40$ & $0.41-0.66$ \\
\hline
\end{tabular}

(3) Integration of indexes and the comprehensive assessment model. On the basis of single-factor analysis in the feature level, the weighted sum method is used to merge integration gradually. This gives eight evaluations of support level indexes and three criteria level indexes. The calculation formula is: 


$$
E_{n}=\sum_{i=1}^{p} w_{i} e_{i}
$$

where $E_{n}$ is the unit combination value of index $n ; p$ is the lower level index number that is included in the index $n ; w_{i}$ is the weight of index $i$; and $e_{i}$ is the hierarchical value or the initial merging value of index $i$.

In order to ensure the comprehensive evaluation not only reflects the general characteristics of regional development potential, but also highlights the effects of restrictive factors, this paper takes the development constraints as negative indexes and the development intensity and potential as positive indexes, and combines them with the current situation in the basin. The main limiting factors are set on the basis of the criterion level evaluation (see Table 2). Then, the comprehensive evaluation value of TDS can be calculated using the dynamic weighted sum method to integrate the index comprehensively:

$$
G=\prod_{j=1}^{L} f_{j}\left(x_{j}\right) \sum_{i=1}^{n} w_{i} d_{i}
$$

where $G$ is the comprehensive evaluation value of the spatial unit; $n$ is the criterion level factor; $L$ is a limiting factor; and $f_{j}\left(x_{j}\right)$ is the limit coefficient of limiting factor $j, 0 \leq f_{j}\left(x_{j}\right) \leq 1$. The greater the $f_{j}\left(x_{j}\right)$ values, the weaker the restriction, and when $f_{j}\left(x_{j}\right)=1$, there is no restriction. $w_{i}$ is the weight coefficient of criterion level factors $i$, which transform on the basis of weight of development constraints and $d_{i}$ is the evaluation value of the criterion layer factors $i$.

Table 2 Limiting coefficients of main limiting factors

\begin{tabular}{cccccccccc}
\hline Index grade & I & II & III & IV & V & VI & VII & VIII \\
\hline Limiting coefficient & 1.00 & 0.98 & 0.96 & 0.94 & 0.92 & 0.90 & 0.88 & 0.86 \\
\hline
\end{tabular}

\section{Results}

\subsection{Distribution of development constraints}

This approach takes the county region as a unit to calculate the actual values of nine element layers. In addition, the single-factor analysis method is used to evaluate the classification in order to reflect the spatial variation pattern of elements in the Yangtze River Basin. On this basis, the values of the development constraints can be calculated using the integrated index values of three support layers that are obtained from the integrated values from the graded layers (1-8). This reveals the grading and spatial variation of development constraints of the Yangtze River Basin (Figure 3a) by applying a natural breaking point approach to divide the value into eight development constraint levels, and conducting spatial statistical analysis on different levels of land areas, resident populations, GDPs and upper-middle-lower reaches distribution patterns of the Yangtze River. The land area accounts for $60.30 \%$ of the total area in the high development constraint area (grades $\mathrm{V}-\mathrm{VIII}$ ). The development constraint of this area is relatively high. Ecological protection and agricultural development are great constraints on the development of industrialization and urbanization. The proportions of resident population and GDP in high-value areas are $32.60 \%$ and $16.80 \%$, respectively. The population distribution is not as sensitive to the ecological constraint intensity as the GDP. 
(a)

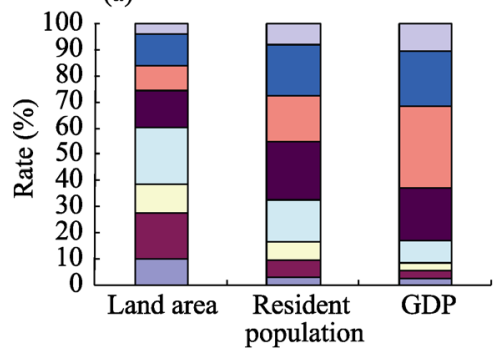

(b)

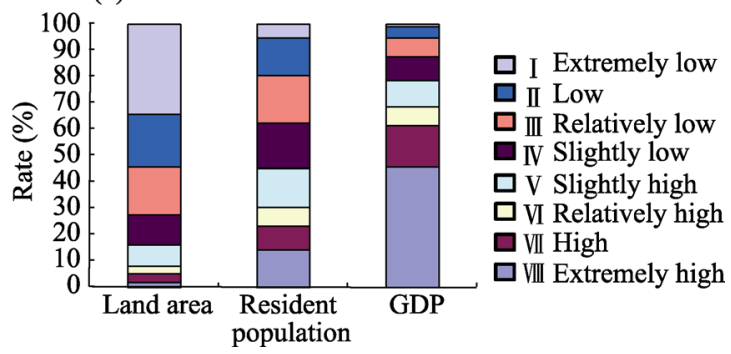

Figure 3 Grading analysis of development constraints (a) and development intensity (b) of the Yangtze River Basin

High development constraint regions are mainly distributed in the upper and middle reaches of the Yangtze River Basin. In the upper reaches, they are approximately distributed in the Hengduan Mountains, the source area of the Yangtze River, Qinling-Daba Mountains, Three Gorges area and the Yunnan-Guizhou Plateau. In the middle reaches of the Yangtze River, the high development constraint regions are spread upstream of the Hanjiang River, western Hubei Mountains, Wuling Mountain, Xuefeng Mountains, Nanling Mountains, Luoxiao Mountains and Tongbai-Dabie Mountain areas. Low development constraint regions are mainly distributed in the Sichuan Basin, Jianghan Plain, Nanyang Basin, Dongting Lake Plain, Poyang Lake Plain and lower reaches of the Yangtze River. The development constraints of Shanghai and Taihu Lake areas are relatively higher than the surrounding areas, but they are still at a low value (Figure 4). In the high-value areas, the numbers of administrative regions of the upper, middle and lower reaches of the Yangtze River are 247, 67 and 1 , while the area weightings are $85.66 \%, 14.13 \%$ and $0.21 \%$, respectively. For the low-value areas, the numbers of administrative regions of the upper, middle and lower reaches of the Yangtze River Basin are 64, 252 and 100, while the area weightings are $16.25 \%, 67.03 \%$ and $16.72 \%$, respectively.

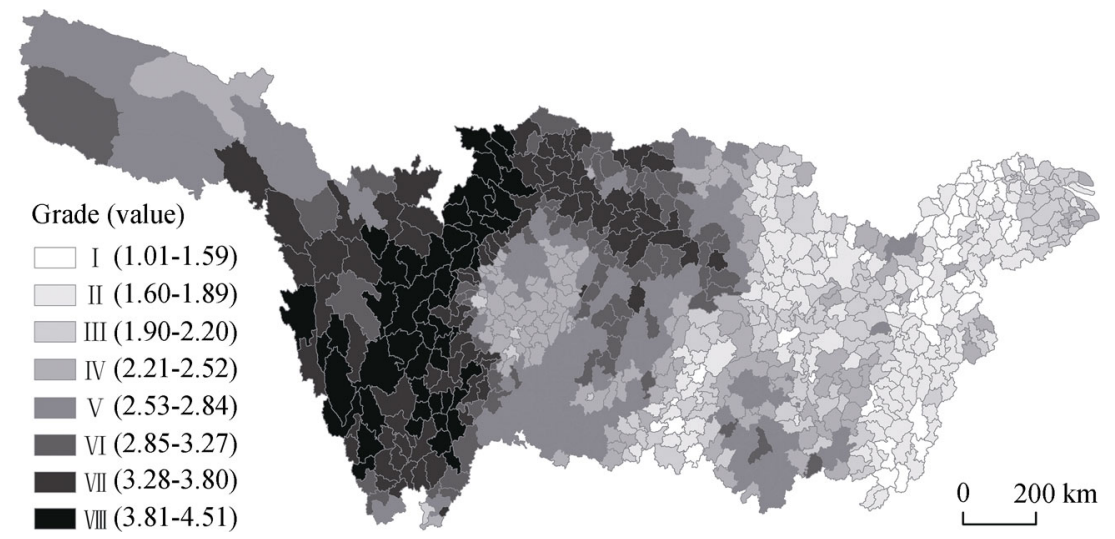

Figure 4 Grading and distribution map of development constraints of the Yangtze River Basin

\subsection{Distribution of development intensity}

Development intensity grades I -VIII show a pyramid structure that reveals a relationship with the decreasing proportion of regional land areas. The land areas in high-value regions 
(grades $\mathrm{V}-\mathrm{VIII}$ ) account for $16.01 \%$ of the total area. The degree of spatial concentration in this region is high, and land space development remains at the accumulation stage. The specific gravity of the resident population and GDP are $44.87 \%$ and $78.21 \%$ in high-value areas. The concentration degree of the spatial distribution of population in the Yangtze River Basin is significantly lower than the degree of economic concentration, which reflects the fact that urbanization development lags behind industrialization and economic development (Figure 3b).

There are obvious regional differences in the development intensity of the Yangtze River Basin. There are high development intensity areas such as the Yangtze River Delta region, Hefei and Maanshan-Wuhu-Tongling regions, Wuhan-Yichang area along the Yangtze River, Changsha-Zhuzhou-Xiangtan urban agglomeration, Nanchang-Xinyu-Fuzhou area, west Chongqing region, Chengdu-Deyang-Mianyang-Leshan district, Guiyang, Kunming and most of the prefecture-level cities. There are also low development intensity areas such as the source area of the Yangtze River, Hengduan Mountains, Wumeng Mountains, Qinling Mountains, Wuling Mountains, western Hubei, Nanling Mountains, southeastern Jiangxi, etc. (Figure 5). In high-value areas, the numbers of administrative regions of the upper, middle and lower reaches of the Yangtze River are 73, 84 and 73, respectively. The area weightings of the upper, middle and lower reaches of the Yangtze River Basin are 30.90\%, 42.97\% and $26.13 \%$, respectively. In the low-value areas, the numbers of administrative regions are 238 , 235 and 28 for the upper, middle and lower reaches, respectively, while the area weightings are $62.86 \%, 33.93 \%$ and $3.21 \%$, respectively.

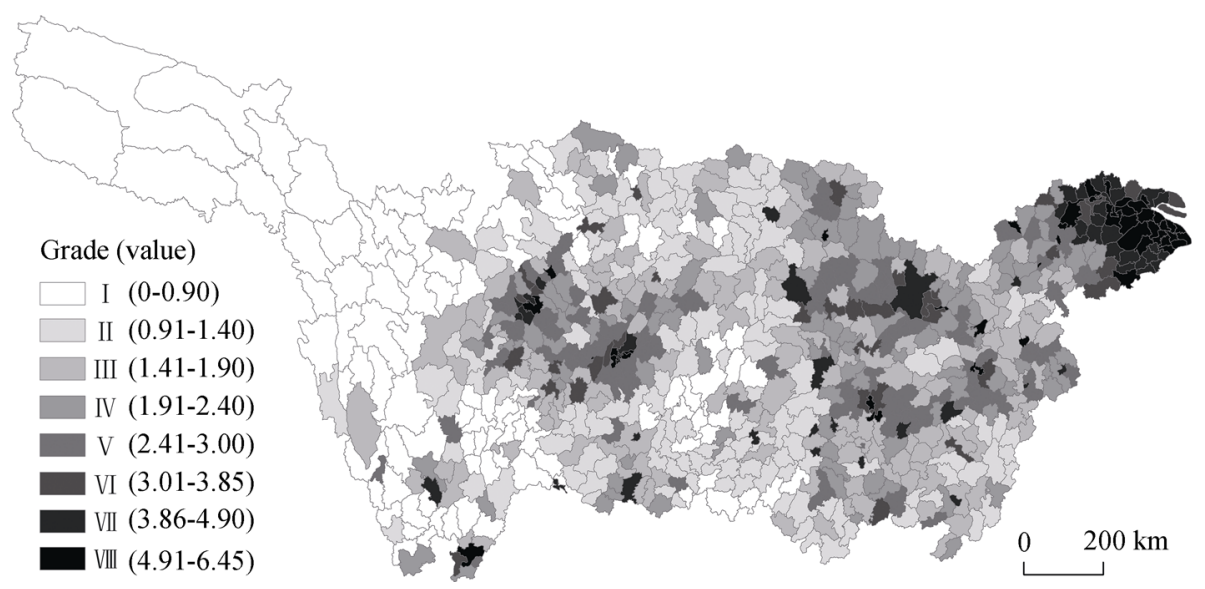

Figure 5 Grading and distribution map of development intensity of the Yangtze River Basin

\subsection{Distribution of development potential}

The indicators of development potential evaluation include economic development potential and degree of traffic superiority. The degree of traffic superiority can be obtained from a calculation of the trunk road network density together with superposition of water elements such as ports and waterways. The proportion of land area significantly decreases in grades I -VIII development potential regions. In high-value areas, the land area accounts for $8.96 \%$ of the total area, which indicates a high degree of spatial concentration of development potential (Figure 6a), and the resident population and GDP in these areas account for $31.26 \%$ 
and $68.06 \%$, respectively. The spatial distribution of population is unreasonable, in view of the low spatial coupling degree between population and economy in the basin.

(a)

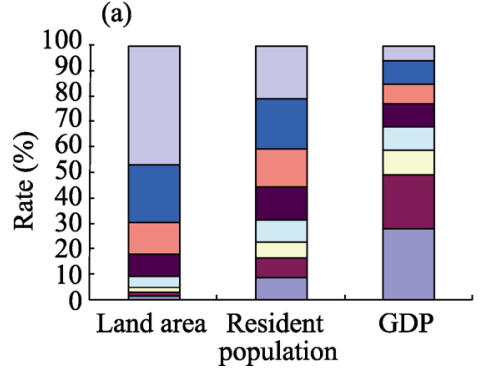

(b)

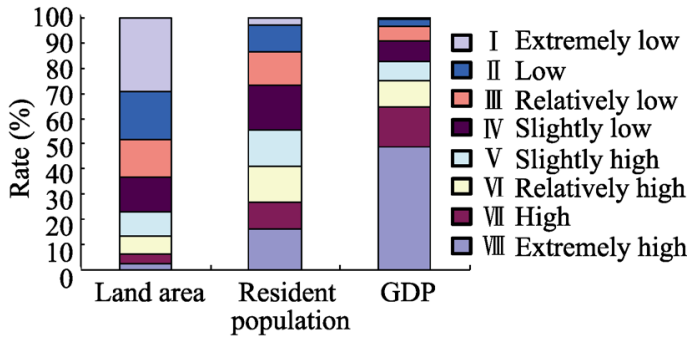

Figure 6 Grading analysis of development potential (a) and TDS (b) of the Yangtze River Basin

The spatial pattern of development potential is similar to that of development intensity, but with even higher concentrations and more significant regional differentiation. Obviously, the middle and lower reaches of the basin are superior to the upper reaches for development potential (Figure 7). If no coordinated regional development policy is taken, then the development gap between regions and different reaches of the Yangtze River Basin will continue to expand. In high-value areas, the numbers of administrative regions of the upper, middle and lower reaches of the Yangtze River Basin are 42, 43 and 64, respectively, and the areas cover $25.08 \%, 32.44 \%$ and $42.48 \%$ of the total areas. In low-value areas, the numbers of administrative regions are 269, 276 and 37, respectively, and the areas cover $60.98 \%$, $35.64 \%$ and $3.38 \%$ of the total areas.

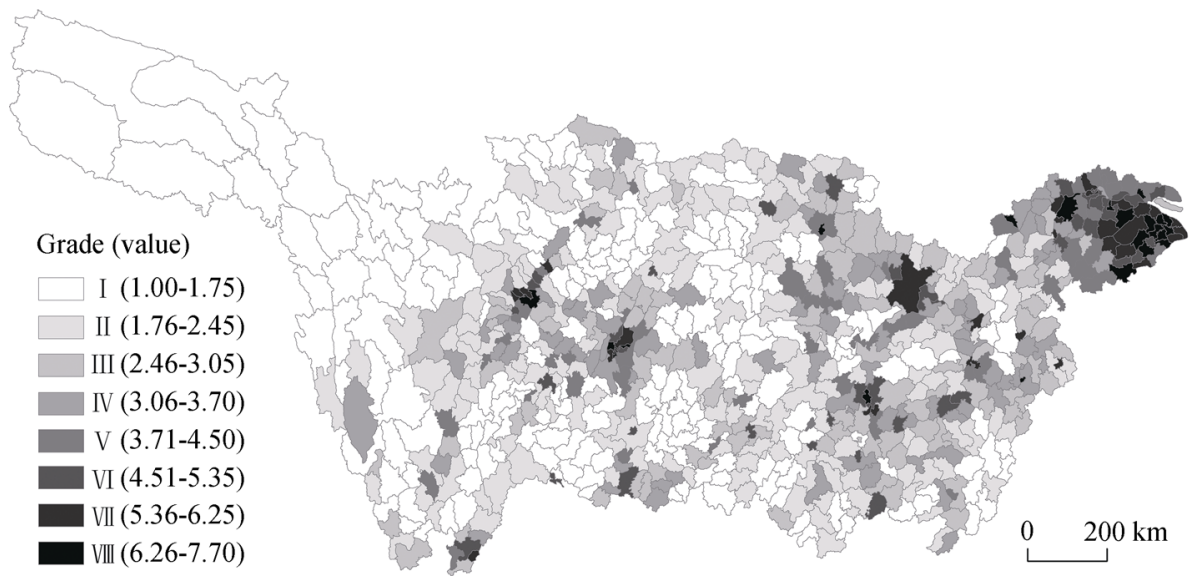

Figure 7 Grading and distribution map of development potential of the Yangtze River Basin

\subsection{Comprehensive evaluation and distribution of TDS}

This paper attempts to achieve grade standard evaluation and classification through the integrated measurement of itemized assessments of development suitability. The areas of regions that have development suitability grades I -VIII (Figure 6b) are significantly decreasing. The land areas with high values (grades $\mathrm{V}-\mathrm{VIII}$ ) only account for $22.95 \%$ of the total area, which indicates that only small parts of the areas are suitable for development, while the remaining areas either have low suitability of regional development or development is 
limited or even prohibited. In high-value areas, the resident population and GDP are 55.39\% and $82.63 \%$, respectively. The phenomenon of cluster development along the Yangtze River Basin will still be dominant in the near future, and moderate population migration among regions must be facilitated and fixed in order to promote population-economic space coupling; otherwise the regional development gap will be increased further.

High development suitability areas include the Yangtze River Delta, Hefei and the area along Wanjiang River, Wuhan urban agglomeration, Jingzhou-Yichang, ChangshaZhuzhou-Xiangtan urban agglomeration, Xiangyang-Nanyang, Nanchang-Jiujiang-Xinyu, Chengdu-Chongqing urban agglomeration, Guiyang-Anshun, Kunming and most of the prefecture-level cities. Low development suitability areas include the source area of the Yangtze River, Hengduan Mountains of western Sichuan-northwestern Yunnan, Wumeng Mountains, Three Gorges area, Qinling Mountains, Wuling Mountains, Nanling Mountains and southeastern Jiangxi (Figure 8). In high-value areas, the numbers of administrative regions of the upper, middle and lower reaches of the Yangtze River Basin are 73, 137 and 89, and the areas cover $20.65 \%, 54.75 \%$ and $24.60 \%$ of the total areas, respectively. In low-value areas, the numbers of administrative regions of the upper, middle and lower reaches are 238,182 and 12 , while the areas cover $68.94 \%, 29.55 \%$ and $1.51 \%$ of the total areas, respectively (Table 3).

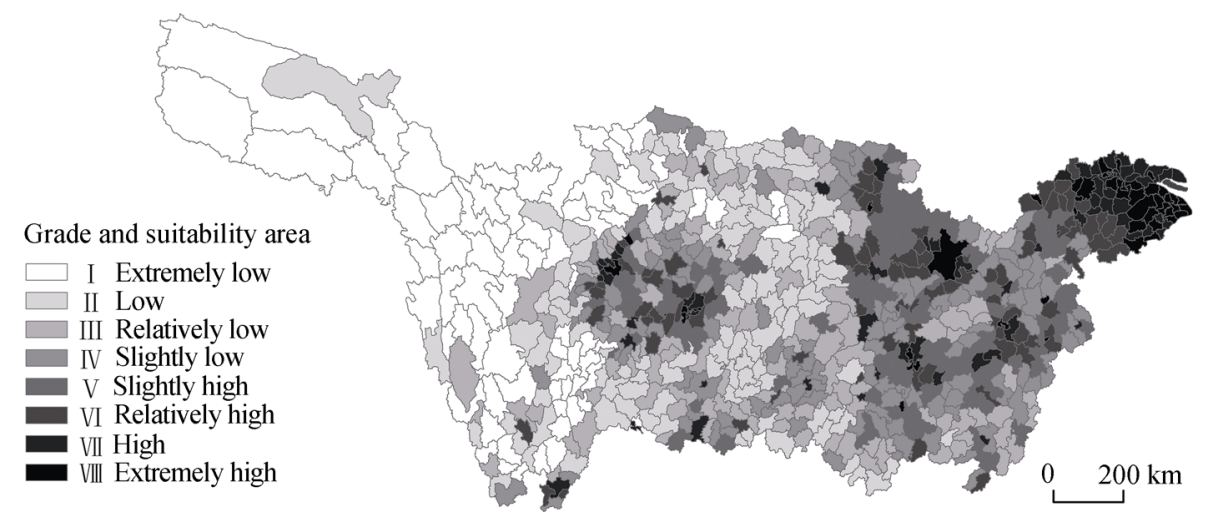

Figure 8 Grading and distribution map of TDS of the Yangtze River Basin

Table 3 Variation of TDS along the upper, middle and lower reaches of the Yangtze River Basin

\begin{tabular}{cccccccc}
\hline $\begin{array}{c}\text { Comprehensive } \\
\text { classification and } \\
\text { value }\end{array}$ & $\begin{array}{c}\text { Number of } \\
\text { administrative } \\
\text { regions }\end{array}$ & $\begin{array}{c}\text { Number of } \\
\text { administrative } \\
\text { regions of the } \\
\text { upper reaches }\end{array}$ & $\begin{array}{c}\text { Number of } \\
\text { administrative } \\
\text { regions of the } \\
\text { middle reaches }\end{array}$ & $\begin{array}{c}\text { Number of } \\
\text { administrative } \\
\text { regions of the } \\
\text { lower reaches }\end{array}$ & $\begin{array}{c}\text { Area ratio } \\
\text { of the upper } \\
\text { reaches (\%) }\end{array}$ & $\begin{array}{c}\text { Area ratio of } \\
\text { the middle } \\
\text { reaches }(\%)\end{array}$ & $\begin{array}{c}\text { Area } \\
\text { ratio of } \\
\text { the lower } \\
\text { reaches } \\
(\%)\end{array}$ \\
\hline I (0.00-1.34) & 73 & 71 & 2 & 0 & 99.24 & 0.76 & 0.00 \\
II $(1.35-2.42)$ & 114 & 75 & 39 & 0 & 71.24 & 28.76 & 0.00 \\
III (2.43-3.47) & 112 & 49 & 61 & 2 & 43.13 & 55.51 & 1.36 \\
IV (3.48-4.57) & 133 & 43 & 80 & 10 & 30.04 & 63.03 & 6.93 \\
V (4.58-5.77) & 96 & 25 & 66 & 5 & 20.73 & 73.64 & 5.63 \\
VI (5.78-7.52) & 89 & 24 & 42 & 23 & 24.60 & 47.16 & 28.24 \\
VII (7.53-10.32) & 66 & 17 & 20 & 29 & 20.86 & 36.13 & 43.01 \\
VIII (10.33-14.15) & 48 & 7 & 9 & 32 & 7.18 & 26.87 & 65.95 \\
\hline
\end{tabular}


There are significant differences in the structures of development suitability among the upper, middle and lower reaches of the Yangtze River Basin. The numbers of administrative regions of the high-value and low-value areas of the upper reaches are $23.47 \%$ and $76.53 \%$, respectively, while the middle reaches are $42.95 \%$ and $57.05 \%$, respectively, and the lower reaches are $88.12 \%$ and $11.88 \%$, respectively. The land area of high-value and low-value areas of the upper reaches cover $8.24 \%$ and $91.76 \%$, respectively, while the middle reaches cover $35.70 \%$ and $64.30 \%$, respectively, and the lower reaches cover $82.97 \%$ and $17.03 \%$, respectively.

\section{Conclusions and policy implications}

\subsection{Conclusions}

The Yangtze River Basin is a vitally important area that supports China's economic development. The vast basin contains many administrative areas, and natural and human factors that are characterized by significant regional differentiations. There are regional variations of TDS, which have an important impact on the unified development and protection of the whole basin. The results show the following.

(1) The Yangtze River Basin has high development constraints. Both ecological protection and agricultural development have strong industrialization and urbanization constraints. High development constraints areas (grades V-VIII) are mainly distributed in the upper reaches, particularly in the Hengduan Mountains, the source area of the Yangtze River, Qinling Mountains, Yunnan-Guizhou Plateau and other areas. There is also a large distribution in the middle reaches, for example, the upstream region of Hanjiang River, Wuling Mountains, Nanling region and other regions, but with less distribution in lower reaches. The development constraints of Shanghai and Taihu Lake area are relatively higher than the surrounding areas.

(2) There are significant decreases in the proportions of land area for regions where the classification of development intensity and potential are in the range I -VIII. The land areas in high-value regions cover less than $20 \%$ of the total area. The degree of spatial concentration in these regions is high and displays a pyramid structure, which means that the land space development remains at the accumulation stage. The spatial pattern of development potential is similar to that of development intensity, but with even higher concentration and more significant regional differentiation. Obviously, the middle and lower reaches of the Yangtze River Basin are superior to upper reaches in terms of development potential.

(3) The land areas of TDS high-value areas (grades V-VIII) only account for $22.95 \%$ of the total area, which indicates that only a small part of the area is suitable for development, while the remaining areas either have low suitability for regional development or development is limited or even prohibited. There are significant differences in the structures and distribution of development suitability among the upper, middle and lower reaches. The high development suitability areas include the Yangtze River Delta, Hefei and the area along Wanjiang, the urban agglomeration in the middle reaches of the Yangtze River Basin, Jingzhou-Yichang, Xiangyang-Nanyang, the Chengdu-Chongqing urban agglomeration, Guiyang-Anshun, Kunming and most of the prefecture-level cities. 


\subsection{Policy implications}

The Yangtze River Basin is a huge system, and so comprehensive, in-depth planning of its development strategy, target, overall layout and development models should be conducted. The planning should respect the laws of nature and socioeconomic development and be based on the economic development trends of China and the Asia Pacific region. The general guiding ideology of territorial development of the basin is that different functions and classification management should be implemented according to differences in the TDS characteristics. That is, the "one-size-fits-all" management mode should be changed, regional economic barriers broken and regional cooperation of division of labor strengthened. The guiding ideology has the following important scientific and practical impacts on the guidance of development and use of the Yangtze River Basin.

(1) Strict control of the development intensity of the Yangtze River Basin, and setting up efficient and well-organized spatial development patterns. Key, restricted and prohibited development region should be classified, mainly based on comprehensive evaluation of TDS. According to the suitability evaluation results of territorial development, attention should be paid to the following two aspects during the development of the Yangtze River Basin. Firstly, the development intensity should be controlled, with strict control exerted over the area ratio between industrialized and urbanized areas. Secondly, there should be an overall plan of the future development pattern of the Yangtze River Basin from the perspective of the main function division and the spatial distribution pattern of development suitability; the development law of the basin and the integrated network should also be considered and discussed.

This paper proposes a spatial structure concept of the Yangtze River Basin development: one dragon's head area, three core areas, three circles, four major axes, eight key clusters (belts) and multiple areas (nodes). The dragon's head area is the city of Shanghai precincts, the three core areas refers to Shanghai, Wuhan and Chongqing, which are located in the upper, middle and lower reaches of the Yangtze River, respectively. The three circles refer to the city circles of the Yangtze River Delta, the middle reaches of the Yangtze River and the city circle of Chengdu-Chongqing. The four axes include two horizontal and two vertical axes, with the two horizontal axes mainly referring to the axis along the Yangtze River and the Shanghai-Yunnan traffic corridor and the two vertical axes mainly referring to the axis along the Beijing-Guangzhou traffic corridor in the middle reaches and Guangyuan-Nanchong-Chongqing-Zunyi-Guiyang development axis in the upper reaches. The eight clusters (belts) include the Kunming-Panzhihua city cluster, Guiyang-Zunyi city cluster, the upstream of the Hanjiang River city belt, Nanyang-Xiangyang city cluster, western Hubei city cluster along the Yangtze River, Wanjiang city belt, southern Hunan city cluster and southern Jiangxi city cluster. Multiple areas (nodes) refer to other urban areas, and mainly have the local level city as the center, including north Sichuan, northeast Chongqing, west Hunan-east Guizhou and east Jiangxi regional central cities, etc. (Figure 9).

(2) Implementation of different regional policies according to different functional orientations. Based on the suitability evaluation and the reality of the Yangtze River Basin, the whole basin should be further divided into different function zones: the optimizing development zone, the key development zone, the agricultural development zone, the ecological protection zone, and so on. In addition, the function orientation and development target of the zones should be determined, and different regional policies, including fiscal policies, 


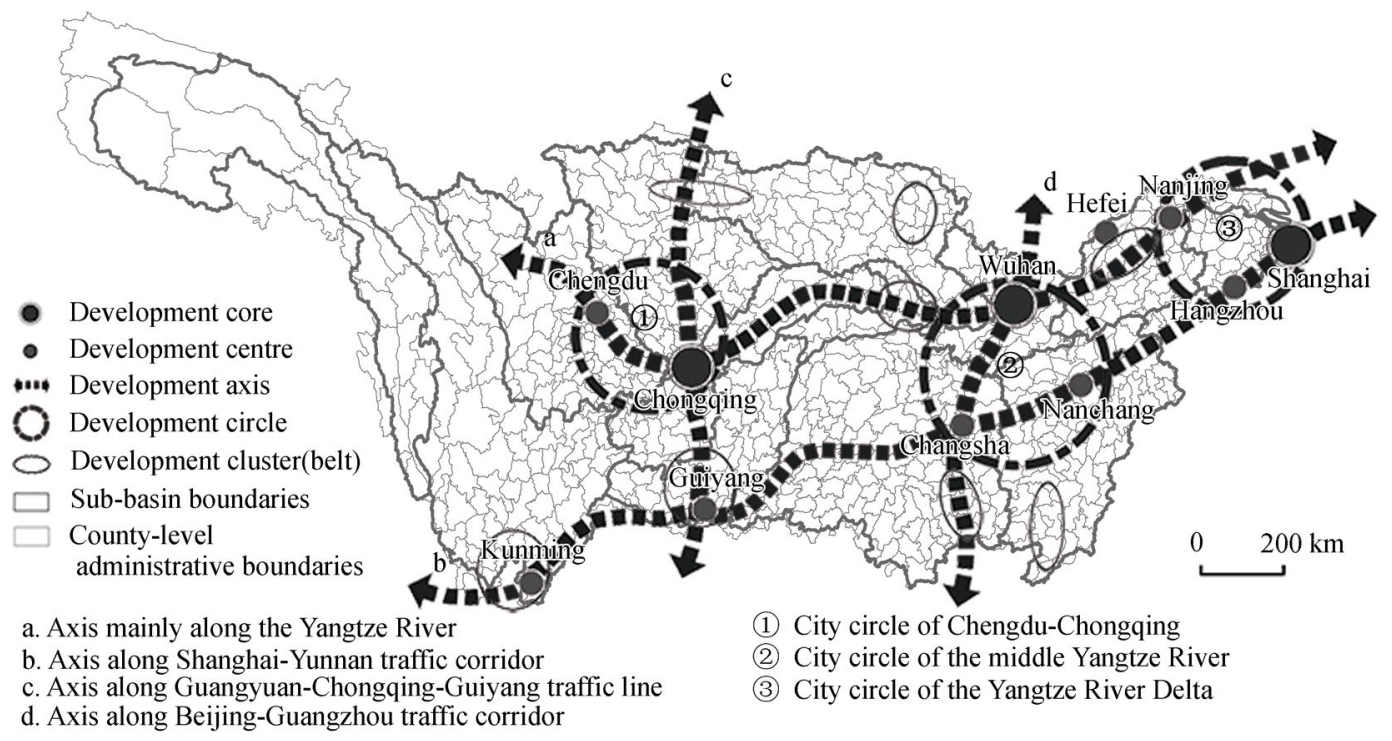

Figure 9 Map of territorial development in the Yangtze River Basin

investment policies, population policies, industrial policies, land policies, environmental policies and government performance evaluation policies formulated and implemented. These should then be integrated with the development layout and policies of the Yangtze River economic belt, pilot work of planning and construction of typical functional areas should be conducted, and the practical experiences based on the above actively explored and summarized. From another point of view, there is great strategic significance for promoting the development of the Yangtze River economic belt. Furthermore, the development strategy should be scientifically based on territorial suitability distribution patterns in order to promote sustainable development and protection of the river basin. The encouraged development areas should vigorously transform the traditional development methods, promote new types of industrialization and urbanization, as well as population agglomeration and industrial-economic development, and make greater contributions to regional development with regards to population and economics. For these areas, industry and modern services should be centralized and arranged in industrial parks (agglomeration district). Meanwhile, resource-saving and environmentally friendly modes of production management should be implemented. Port logistics and comprehensive transportation should be enhanced and form node-hub-corridor-networks transportation system. In other areas, support for nature reserves, ecological barriers, ecological corridors and agricultural production areas should be increased, in addition to increasing comprehensive regional compensation. These areas should also vigorously explore the land transfer mechanism and technology promotion mechanism, make good use of agricultural and ecological resources, and develop the ecological economy. At the same time, the government should weaken the economic growth index evaluation of these regions and support them in policies and mechanisms. This can aid environmentally-friendly development and promote the construction of ecological civilization, in order to provide effective protection for basin-wide ecological security and sustainable development.

(3) Strengthening of communication and division of labor cooperation, promoting inte- 
grated protection and development. To achieve sustainable development of the Yangtze River Basin, it not only necessary to classify the planning and management of each region, but also the interaction and coordination among different reaches and regions of the Yangtze River Basin need to be strengthened, which can result in division of labor cooperation and shared growth. The Yangtze River is a primary waterway that achieves the largest volume of freight in the world. The Yangtze River channel is the most important east-west axis in China's territorial development and possesses a significant strategic position in the development of integration in the Yangtze River Basin. Therefore, the shipping functions of the main stream and its tributaries should be strengthened. Various modes of transport connection should be improved, the construction of multimodal transport development accelerated, comprehensive and integrated transport corridor established, to make Yangtze River has more powerful radiation and lead development of the basin. In addition, population distribution, economic layout and resources and environment carrying capacity should be coordinated to improve the efficiency of factor allocation and strengthen regional interaction, synergy and coupling development on the basis of the comparative advantages of different sections and different regions of the Yangtze River Basin. The middle-upstream area and protected regions should make full use of regional ecological resources and labor advantages, strengthen the cooperation with the Yangtze River Delta in transfer of industry, economic and technical cooperation, and personnel training, and actively develop ecological agriculture, the environmental-protection industry, eco-tourism and characteristic industries, and implement diversified development. In order to implement the integration of ecoenvironmental protection, a planning, construction, monitoring and management platform should be constructed that is suitable for the eco-environmental protection of the whole Yangtze River Basin, and the compensation mechanism for protected and upstream regions should be improved. The compensation mechanism mainly includes ecological and agricultural compensation. The construction of administrative organization and regional coordination mechanisms should also be strengthened. As the Yangtze River Basin has such a vast size and wide coverage, in order to manifest its advantage, the administrative barriers of regions along the Yangtze River and in its basin should be broken, with the establishment of integrative management organization, building and improving the regional coordination mechanism that manages the basin overall. At the same time, the basin management concept needs to be updated, and ecological construction and environmental protection taken as important goals of integrated basin management.

\section{References}

Banai R, 1993. Fuzziness in geographical information systems: Contributions from the analytic hierarchy process. International Journal of Geographical Information Systems, 7(4): 315-329.

Batty M, Xie Y, 1994. From cells to cities. Environment and Planning B, 21(7): 31-48.

Burrough P A, McDonnell R A, 1998. Principles of Geographical Information Systems. Oxford: Oxford University Press.

Carver S J, 1991. Integrating multi-criteria evaluation with geographical information system. International Journal of Geographical Information System, 5(3): 321-339

Chen W, Yu X G, 1997. Characteristics, problems and development strategy in regions along the Changjiang River. Scientia Geographica Sinica, 17(2): 113-119. (in Chinese)

Chen Y N, He X A, Zhang X Y, 2007. River basin development and land management patterns-simultaneously on 
land development and industry positioning in the Ili River Basin. Arid Land Geography, 30(4): 595-600. (in Chinese)

Ding J Z, Chen Y, Chen W, 2008. Regionalization of spatial feasible development on based analysis of eco-economy in Taizhou City. Scientia Geographica Sinica, 28(6): 842-848. (in Chinese)

Fan J, 2007. The scientific foundation of major function oriented zoning in China. Acta Geographica Sinica, 62(4): 339-350. (in Chinese)

Fan J, Pan W F, Hu D S et al., 2011. A Research on Sustainable Development of Xijiang Economic Belt (Section of Guangxi): Function, Process and Pattern. Beijing: Science Press. (in Chinese)

Fan J, Tao A J, Lv Ch, 2010. The coupling mechanism of the centroids of economic gravity and population gravity and its effect on the regional gap in China. Progress in Geography, 29(1): 87-95. (in Chinese)

Ge M L, Feng Z M, 2009. Population distribution of China based on GIS: Classification of population densities and curve of population gravity centers. Acta Geographica Sinica, 64(2): 202-210. (in Chinese)

Guo Zh G, 2002. Social Statistical Methods and the Application of SPSS. Beijing: China Renmin University Press. (in Chinese)

He Y B, Chen Y Q, Yang P et al., 2009. An overview and perspective of alien land suitability evaluation study based on GIS technology. Progress in Geography, 28(6): 898-904. (in Chinese)

Krzanowski R, Raper J, 2001. Spatial Evolutionary Modeling. Oxford: Oxford University Press.

Li N, 2009. Regionalization of feasible development in Yizheng City based on GIS. Areal Research and Development, 28(2): 123-128. (in Chinese)

Liu S J, 1998. Economic Development and Comparative Study among the Upper, Middle and Lower Reaches of the Yangtze Basin. Wuhan: Huazhong Normal University Press. (in Chinese)

Liu Z D, Yu X G, Wang Z X, 2003. The current water pollution of Taihu drainage basin and the new management proposals. Journal of Natural Resources, 18(4): 467-474. (in Chinese)

MacDougall E B, 1975. The accuracy of map overlays. Landscape Planning, 2: 23-30.

Malczewski J, 1999. GIS and Multi-criteria Decision Analysis. New York: Wiley.

Murray T, Roger P, Sinton D et al., 1971. Honey Hill: A systems analysis for planning the multiple uses of controlled water areas. 2 vols. Report Nos. AD736343 and AD736344. National Technical Information Service, Springfield, Virginia.

Openshaw S, Abrahart R J, 2000. Geo-Computation. London: Taylor \& Francis.

Qi Y W, Gu C L, 2010. Study on the methods and their application for the urban development spatial division: A case of Nanjing. Geographical Research, 29(11): 2035-2044. (in Chinese)

She Z X, 1994. On the exploitation, opening to the outside world and studies on geography of the Yangtze River Basin. Acta Geographica Sinica, 49(Suppl.): 729-736. (in Chinese)

Sui D Z, 1993. Integrating neural networks with GIS for spatial decision-making. Operational Geographer, 11(2): 13-20.

Sun W, Chen W, 2009. Regionalization of spatial potential development and distribution guidance: A case study of Ningbo city. Journal of Natural Resources, 24(3): 402-413. (in Chinese)

Steinitz C, Parker P, Jordan L, 1976. Hand drawn overlays: Their history and prospective uses. Landscape Architecture, 9: 444-455.

Wang F, Brent Hall G, Subaryono, 1990. Fuzzy information representation and processing in conventional GIS software: Database design and applications. International Journal of Geographical Information System, 4: 261-283.

Wang X C, Rong F, 2010. Comprehensive planning and sustainable development of Yangtze River Basin. Yangtze River, 41(4): 5-8, 18. (in Chinese)

Wei H K, Jiang Y Y, 2009. Development planning of the Yangtze River Basin Area: Present situation and prospect. Learning and Practice, 11: 5-13. (in Chinese)

Yu X G, 2003. Study on Sustainable Development of the Yangtze River Basin. Beijing: Science Press. (in Chinese)

Zhang W H, 1991. Theories and methods of economic zoning of river basin. Tianfu New Forum, 6: 28-34. (in Chinese)

Zhu C G, Ma X D, Meng Z Y et al., 2007. The Theory, Method and Case of Regional Major Function Oriented Zoning. Beijing: Science Press. (in Chinese) 